\title{
The knowledge and use of population- based methods for caries detection
}

\author{
Ana Luiza Sarno Castro $^{1 *}$ D, Maria Isabel Pereira Vianna ${ }^{2}$ and Carlos Maurício Cardeal Mendes ${ }^{3}$
}

\begin{abstract}
Background: Since the 1980s, a wide variety of methods have been proposed to measure dental caries in the population, demonstrating a lack of consensus regarding the procedure that should be used for this purpose. The current study investigated the methods that are known and used by public oral health researchers and professors as well as the reasons that lead to the choice of a particular method.

Method: In the context of an interview, a questionnaire was administered to public oral health researchers and professors who used caries indices and worked in Salvador and Feira de Santana, Bahia, Brazil from 2005 to 2015. A quantitative and descriptive approach was applied that adopted the multiple correspondence analysis (MCA) technique to assess the associations among responses.

Results: The decayed, missing, and filled index (DMF) was the only measurement known by all respondents, and although 45 of the 47 professors/researchers were dissatisfied with this index, only six had used other methods. This index was chosen because of its comparability and ease of application. The MCA revealed response associations among older, male participants who graduated from the Federal University of Bahia (UFBA) and who continued to use this index because of its comparability and because it is the index recommended by the World Health Organization (WHO) and the Brazilian Ministry of Health (MS). Another group was also observed that consisted of younger females who graduated from the State University of Feira de Santana (UEFS) or another university and who used the DMF because it is well-known, simple, and easy to apply.

Conclusions: The DMF index was the most known and used method. Many respondents demonstrated a desire for change and were critical of the DMF; however, they did not know of and had not used newer methods for measuring dental caries. Greater importance should be placed on the problem of dental caries assessment in the population.
\end{abstract}

Keywords: Epidemiology, DMF, New indexes, Use, Knowledge, Surveys, Oral health

\section{Background}

The use of effective methods to assess caries in a population determines the quality of information obtained from epidemiological surveys, which in turn affects the diagnostic accuracy of this condition and is the basis for the planning, monitoring, and assessment of oral health prevention and disease control actions [1].

Several methods are used to measure dental caries in the population. The most widely used index is the decayed, missing, and filled (DMF) assessment described by Klein and Palmer in 1937 [2]. However, this index was created before the decrease in the incidence of caries and

\footnotetext{
* Correspondence: alscastro@yahoo.com.br

${ }^{1}$ Department of Health, State University of Feira de Santana, Transnordestina, $\mathrm{s} / \mathrm{n}$, Novo Horizonte, Feira de Santana, Bahia CEP 44036-900, Brazil Full list of author information is available at the end of the article
}

the advances in cariology that have occurred over the past decades that emphasises the importance of early diagnosis and early treatment for initial caries lesions. For these reasons, the DMF does not include non-cavitated enamel caries lesions among its components [3].

The use of the DMF has been questioned because of its limitations [3]. Since the 1980s, several authors have proposed different methods to assess caries lesions, such as the NYVAD System [4], the Significant Caries Index (SIC) [5], the Sound-Equivalent Teeth (T-Health) [6], the Filled and Sound Teeth (FS-T) [6], the Reversible Dental Caries Index (IRCD; Indice Reversivel de Cárie Dental), the Caries Activity Index (IAC; Índice de Atividade de Cárie) [7], and many others [8-10]. Among the new methods used to assess caries in a population is the International Caries

(c) The Author(s). 2018 Open Access This article is distributed under the terms of the Creative Commons Attribution 4.0 International License (http://creativecommons.org/licenses/by/4.0/), which permits unrestricted use, distribution, and 
Detection and Assessment System (ICDAS) [11] and the Caries Assessment Spectrum and Treatment (CAST) [12], which have both been internationally validated by several studies [13-15].

The number of methods proposed in recent decades demonstrates that the diagnosis of caries in a population is an important topic and that no consensus exists among researchers with regard to the most appropriate method for making a diagnosis [3]. As such, the current study aimed to identify the caries assessment systems that are known among public oral health researchers and professors, what methods they currently use, and the reasons behind their method of choice.

\section{Methods}

The present study employed an exploratory cross-sectional opinion poll with convenience sampling (Additional file 1). Through an interview, a semi-structured questionnaire was developed by the authors and administered to public oral health researchers and professors who used caries indices in Salvador and Feira de Santana, Bahia, Brazil, from 2005 to 2015 .

The regions of Feira de Santana and Salvador were chosen for this study because they contain $43.8 \%$ of the dental schools in Bahia (14 of the 32 dental schools that existed in Bahia at the time of the interview) [16], and Salvador is among the 10 cities in Brazil with the most specialists registered in the Federal Council of Dentistry of Brazil [17].

Two search procedures were conducted to identify the study population: First, professors who teach public oral health at dental institutions in Salvador and Feira de Santana were identified; second, a search was performed using the PubMed, Lilacs, SciELO, and Google Scholar databases for researchers who had published articles describing their use of caries assessment methods during the stated period. Ultimately, 50 individuals met the study's eligibility criteria.

The respondents formalised their acceptance by signing informed consent documents. This study was approved by the Research Ethics Committee of the Sciences Institute of the Federal University of Bahia, under CAAE number 48500115.2.0000.5662.

Instrument pre-testing was conducted with six dental professors who were subsequently excluded from the sample. This pre-test was performed from October 10 to 15 , 2015, and the interviews were conducted from October 16, 2015 to March 8, 2016. The principal researcher conducted face-to-face interviews at the universities, offices, or houses of the interviewees based on their preference. The interviews lasted an average of $20 \mathrm{~min}$ and were recorded and then transcribed. The data were entered into the EPIDATA program and analysed using R statistical software [18].

A quantitative and descriptive analysis was conducted. The multivariate analysis technique known as a multiple correspondence analysis (MCA) was used. This tool allows for a set of categorical variables to be assessed based on both their intensity and degree of association [19].

\section{Results}

Of the 50 individuals who were identified based on the search procedures, 47 agreed to participate. Their mean age was 46 years, with a standard deviation of 8 years. The mean time since graduation was 22 years, with a standard deviation of 8 years. Most participants were female (70.2\%). Moreover, 28 individuals had graduated from UFBA (59.6\%), 13 from UEFS (27.7\%), and six (12.7\%) from other universities (see Table 1).

Of the interviewees, $39(83 \%)$ were public oral health professors, and 27 (57.4\%) reported having performed research using caries assessment methods between 2005 and 2015. Of the individuals who were not university professors, five $(10.6 \%)$ worked in the private sector (in offices), and three (6.4\%) worked in the public sector (i.e., state organisations).

With regard to the specialties of the interviewees, 23 (48.9\%) had postgraduate degrees in public health, three in health management (6.4\%), and six (12.8\%) in teaching methodology. The remaining 15 (32\%) had specialties in other areas.

Table 1 The distribution of professors and researchers by their personal characteristics, academic training, and place of work

\begin{tabular}{|c|c|c|}
\hline VARIABLES & Number & Percent \\
\hline \multicolumn{3}{|l|}{ SEX } \\
\hline Female & 13 & 70.2 \\
\hline Male & 14 & 29.8 \\
\hline \multicolumn{3}{|l|}{ AGE } \\
\hline Between 30 and 50 years & 35 & 75.4 \\
\hline Between 51 and 70 years & 12 & 24.6 \\
\hline \multicolumn{3}{|l|}{ TIME SINCE GRADUATION } \\
\hline Between 8 and 17 years & 12 & 24.6 \\
\hline Between 18 and 47 years & 35 & 75.4 \\
\hline \multicolumn{3}{|l|}{ PLACE OF GRADUATION } \\
\hline UFBA & 28 & 59.6 \\
\hline UEFS & 13 & 27.7 \\
\hline Other universities & 6 & 12.7 \\
\hline \multicolumn{3}{|l|}{ PLACE OF WORK ${ }^{a}$} \\
\hline UEFS & 19 & 40.4 \\
\hline UFBA & 18 & 38.3 \\
\hline Other universities & 10 & 21.3 \\
\hline Municipal or state health agency & 8 & 17.0 \\
\hline Private practice & 5 & 10.6 \\
\hline
\end{tabular}

${ }^{a}$ The total number of responses is greater than the number of respondents because some respondents worked at more than one institution 
Table 1 shows that most professors worked at UEFS $(40.4 \%)$ or UFBA (38.3\%); the other 10 respondents $(21.3 \%)$ worked at six different private universities or at the State University of Bahia (UNEB).

In response to the question about the indices that they knew, all respondents reported that they knew of the DMF and DMF with other indices, whereas 25 individuals (53.19\%) knew of only the DMF. In addition, 22 respondents mentioned other indices (46.81\%); of these participants, 16 (34\%) knew of the ICDAS, five (10.6\%) recalled the T-Health and FS-T, four (8.5\%) mentioned the NYVAD, three $(6.4 \%)$ recalled the SIC, IRCD, and IAC, and two (4.3\%) knew the CAST (see Fig. 1 and Table 2).

All of the professors taught the DMF index in their theory- (lectures) and practice-based classes. In addition to the DMF, three lectured on the ICDAS, and two addressed prevalence and incidence density measures. In practical classes, only one professor used the ICDAS, and one applied the prevalence coefficient (see Table 2).

According to Table 2, all respondents reported having had lectures and practical classes on the DMF during their degree programme. Only one respondent claimed to have learned about a different index during their programme. Most taught only the DMF in lectures (87.2\%) and practical classes (94.9\%).

All respondents said they had used the DMF index; of this group, 41 participants $(87.2 \%)$ used only the DMF, and six used other indices (12.7\%). Only the ICDAS, NYVAD, SIC, and incidence density measurements were used in practice at any time by the professionals (see Fig. 2 and Table 2).

The main reason given by respondents regarding their index of choice was the possibility of later data comparisons (66.0\%), followed by the WHO and Brazilian Ministry of Health (MS) recommendations (55.3\%), and

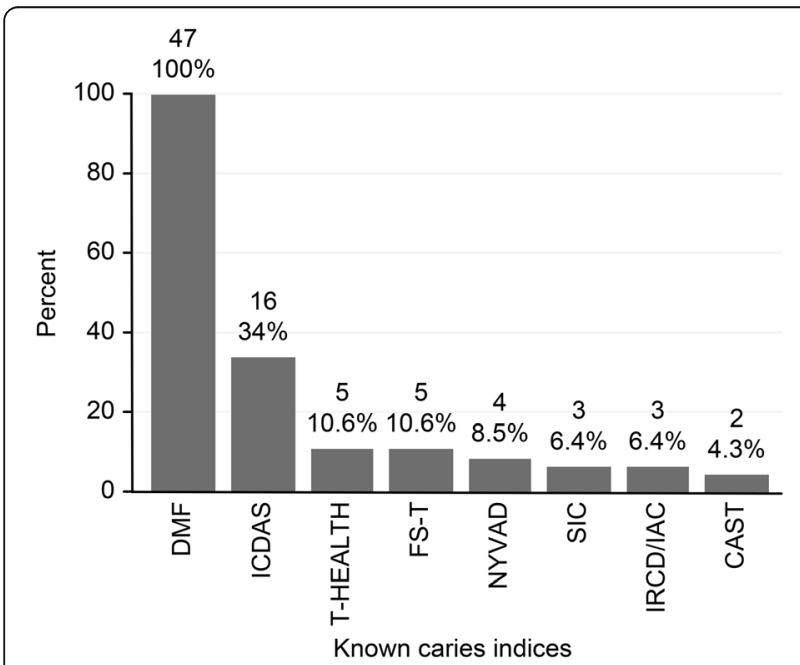

Fig. 1 Knowledge of caries detection methods among public oral health professors and researchers
Table 2 The distribution of professors and researchers by knowledge and use of indices

\begin{tabular}{lll}
\hline VARIABLES & Number & Percent \\
\hline KNOWN INDICES & & \\
DMF and DMF with other indices & 47 & 100.0 \\
Only DMF & 25 & 53.2 \\
DMF index and other indices & 22 & 46.8 \\
USED INDICES & & \\
DMF and DMF with other indices & 47 & 100.0 \\
Only DMF & 41 & 87.2 \\
DMF index and other indices & 06 & 12.8
\end{tabular}

INDICES LEARNED IN THE DEGREE PROGRAMME

$\begin{array}{lll}\text { DMF and DMF with other indices } & 47 & 100.0 \\ \text { Only DMF } & 46 & 97.9 \\ \text { DMF index and other indices } & 01 & 2.1\end{array}$

INDICES TAUGHT IN LECTURES

$\begin{array}{lll}\text { DMF and DMF with other indices } & 39^{\mathrm{a}} & 100.0 \\ \text { Only DMF } & 34 & 87.2 \\ \text { DMF index and other indices } & 05 & 2.8\end{array}$

INDICES TAUGHT IN PRACTICAL CLASSES

\begin{tabular}{lll} 
DMF and DMF with other indices & $39^{\mathrm{a}}$ & 100.0 \\
Only DMF & 37 & 94.9 \\
DMF index and other indices & 02 & 5.1 \\
\hline The total number of public oral health professors was 39 individuals
\end{tabular}

because it is the most widely known index (29.8\%). Ten respondents $(21.3 \%)$ cited its ease of application (see Table 3).

According to Table 3, all participants said they had used the DMF index. The most cited advantages of this index were its ease of application (40.4\%), comparability

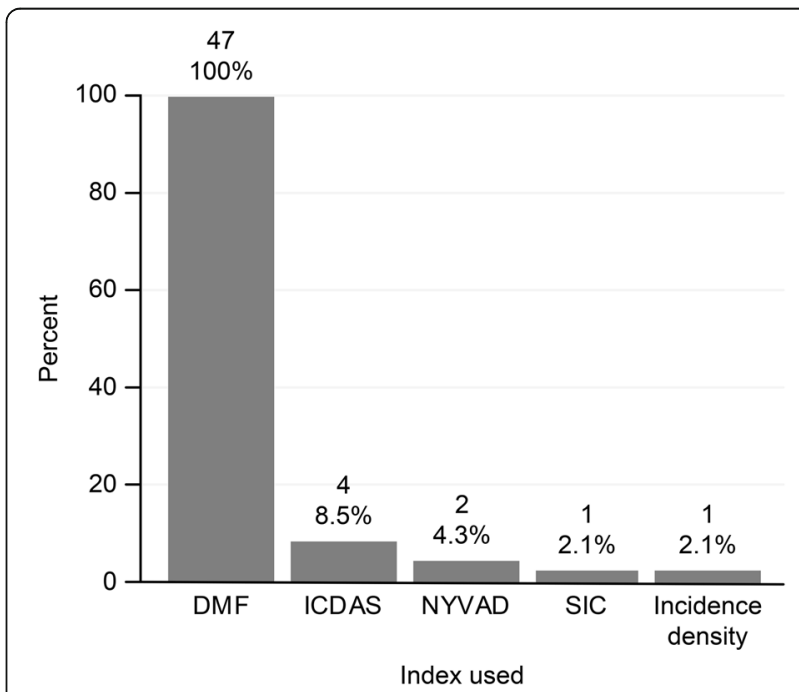

Fig. 2 Use of caries detection methods among public oral health professors and researchers 
(38.3\%), and the fact that it is widely known (19.1\%). The most cited disadvantage of this index was that it does not allow for the detection of enamel lesions (40.4\%). The second most cited disavantage was that it underestimates the prevalence of caries (19.1\%), and the fact that the mean DMF value does not discriminate among decayed, missing, and filled teeth (14.9\%).

As Table 3 shows, being difficult to apply (31.9\%) and complex $(27.7 \%)$ were the most frequently reported reasons for not using an index. Comparability (21.3\%) was the second most mentioned reason to prefer an index, which was also described as the main reason for choosing one $(66.0 \%)$.

Table 3 The distribution of professors and researchers by their reason for choosing an index

\begin{tabular}{|c|c|c|}
\hline VARIABLES & Number & Percent \\
\hline \multicolumn{3}{|l|}{ REASON FOR CHOOSING AN INDEX ${ }^{a}$} \\
\hline Comparability & 31 & 66.0 \\
\hline WHO or MS recommended & 26 & 55.3 \\
\hline Very well known & 14 & 29.8 \\
\hline Easy to apply & 10 & 21.3 \\
\hline \multicolumn{3}{|l|}{ ADVANTAGES OF THE DMF } \\
\hline Easy to apply & 19 & 40.4 \\
\hline Comparability & 18 & 38.3 \\
\hline Very well known & 9 & 19.1 \\
\hline Others & 1 & 2.2 \\
\hline \multicolumn{3}{|l|}{ DISADVANTAGES OF THE DMF } \\
\hline Does not assess enamel lesions & 19 & 40.4 \\
\hline Underestimates caries prevalence & 9 & 19.2 \\
\hline Mean value does not discriminate components & 7 & 14.9 \\
\hline Others & 12 & 25.5 \\
\hline \multicolumn{3}{|l|}{ REASONS FOR NOT USING AN INDEX } \\
\hline Difficult to apply & 15 & 31.9 \\
\hline Complex & 13 & 27.7 \\
\hline Difficult calibration & 7 & 14.9 \\
\hline Time consuming & 7 & 14.9 \\
\hline Others & 5 & 10.6 \\
\hline \multicolumn{3}{|l|}{ REASONS FOR PREFERRING AN INDEX } \\
\hline Ease of application & 2 & 25.5 \\
\hline Comparability & 10 & 21.3 \\
\hline More accurately evaluates caries & 7 & 14.9 \\
\hline Speed & 6 & 12.8 \\
\hline Others & 12 & 25.5 \\
\hline \multicolumn{3}{|l|}{ WOULD USE AN INDEX OTHER THAN THE DMF } \\
\hline Yes & 42 & 89.4 \\
\hline No & 5 & 10.6 \\
\hline
\end{tabular}

${ }^{a}$ The total number of responses is greater than the number of respondent because some of the respondents provided more than one answer
In the sample analysed, 45 of the 47 respondents claimed to be dissatisfied with the DMF index (95.7\%). Nevertheless, the DMF was the most widely used index and was known by all respondents. When criticisms of the indices were surveyed, respondents said that new indices should be used (36.2\%), that these indices should overcome the limitations of the DMF (21.3\%), and that the latter needs be replaced with other caries assessment methods (17\%; see Table 4).

Five respondents stated that they would not use new indices; these participants were over 40 years of age. Two participants said that they were satisfied with the DMF, and three stated that they did not know other methods to measure caries and therefore would not use new indices.

According to the respondents' suggestions, the methods used to assess caries must be easy to understand (36.2\%) and apply (19.1\%). They believe that it is necessary to overcome the accommodation of using only the DMF (14.9\%) and that enamel lesions should be included (12.8\%; see Table 4).

Figure 3 displays a graphical representation of the MCA on a two-dimensional plane. This method jointly assesses how the responses are presented, without dependency relationships or prior assumptions; similar responses are presented graphically on the opposite side to dissimilar ones.

By analysing the point projections on the axes, the responses are categorised into four different groups so that the variables belonging to each group are close together and therefore associated. The groups in opposite quadrants have large distances between their projections, thereby indicating great dissimilarity among these responses.

In the upper left quadrant group, the proximity of the points indicates associations among those who graduated from UFBA; they were older (45-60 years), male, knew indices other than the DMF, recognised the disadvantages of the DMF with regard to underestimating caries but continued to use the index because of its comparability and because it is the index recommended by the World Health Organisation (WHO) and the Brazilian Ministry of Health (MS), and would not accept using an index that was complex, difficult to apply, or time consuming.

In the lower right quadrant, the variables associated form a group composed of females who graduated from UEFS or another university; they were younger (20-45), did not know indices other than the DMF, thought new research should be conducted to find new indices to assess caries, and suggested that these new indices should be simple. They used the DMF because it is widely known; however, they did not mention that this index is recommended by the WHO or MS, and their main reason for preferring an index was its ease of application.

The lower left quadrant shows a group consisting of those mentioning comparability as an advantage of the DMF and who also cited comparability as a reason for 
Table 4 Distribution of professors and researchers by their suggestions and most frequent index criticisms

\begin{tabular}{lll}
\hline VARIABLES & Number & Percent \\
\hline SATISFIED WITH THE DMF & 2 & 4.3 \\
Yes & 45 & 95.7 \\
No & & \\
SUGGESTIONS & 17 & 36.2 \\
$\quad$ Simple and easy to understand & 9 & 19.1 \\
Easy to apply & 7 & 14.9 \\
Overcome the accommodation of using only the & & \\
DMF & 6 & 12.8 \\
Assesses enamel lesions & 8 & 17.0 \\
Others & & \\
CRITICISMS & 17 & 36.2 \\
New indices should be used & 10 & 21.3 \\
Should overcome the DMF's limitations & 8 & 17.0 \\
Replace the DMF with another index & 7 & 14.9 \\
Research how to improve indices & 5 & 10.6 \\
Others
\end{tabular}

choosing or preferring an index. In the upper right quadrant, an association was found regarding responses indicating ease of application as an advantage of the DMF, who tended not to mention comparability as a reason to choose or prefer an index, and who did not mention comparability as an advantage of the DMF.

\section{Discussion}

According to the results presented, most people interviewed were female (70.2\%), these results are in line with several studies that have shown the increasing participation of women in dental schools in Brazil [20-23].

All of the participants interviewed knew of the DMF index, but only 22 knew other caries assessment methods. Interestingly most professors taught only this index, reproducing what they had learned during their own training. Consequently, new generations of professionals will likely continue to be unaware of alternative methods.

The DMF was also the index most used by respondents, even though the vast majority of individuals surveyed claimed to be dissatisfied with it (only two people reported satisfaction). The explanation for this discrepancy lies in the reasons that led the respondents to choose an index. According to the correspondence analysis, the group who was older, male, and trained at UFBA, chose the DMF because of its comparability and

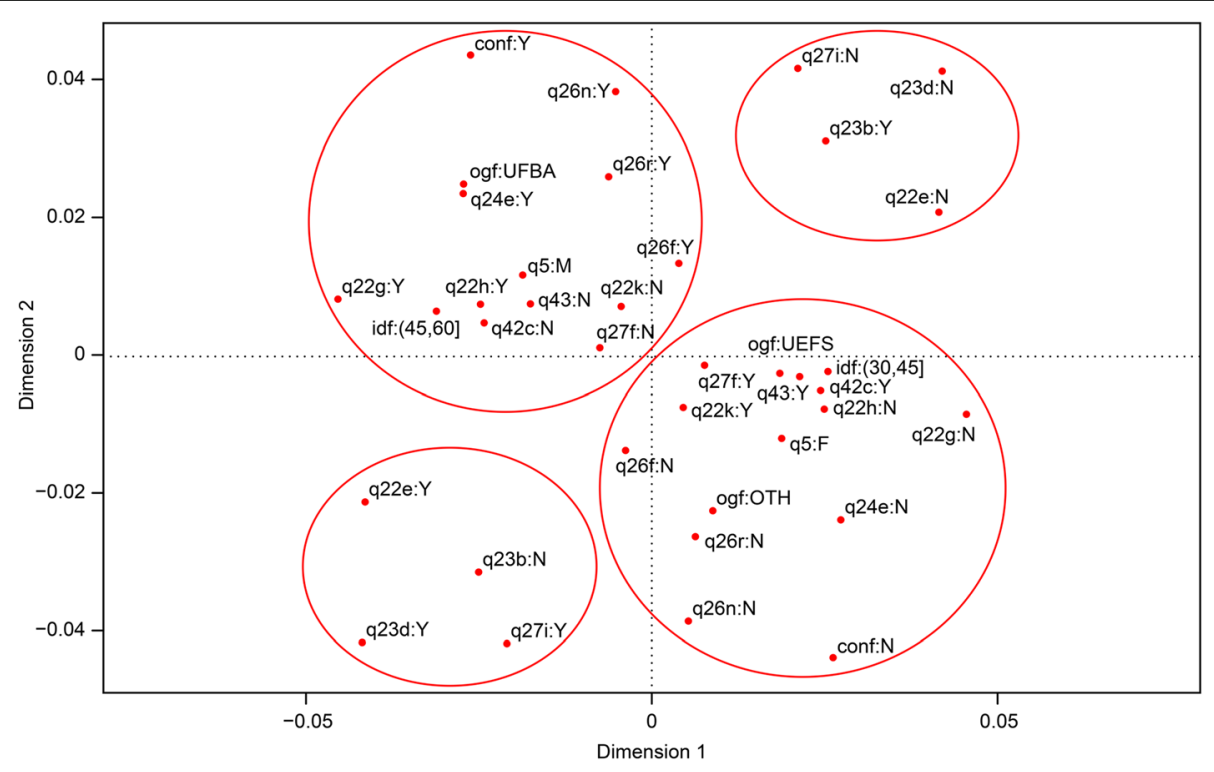

Fig. 3 The MCA of the responses of public oral health professors and researchers. legend: ogf - place of graduation, idf - age, qusof - used an index other than DMF, q5 - sex, indf - individual knows an index other than DMF, q22g - reason for choice was WHO recommendation, q22e - reason for choosing index was comparability, q22h - reason for choice was MS recommendation, q22k - reason for choosing index was it is well known, q23b - DMF's advantage is ease of application, q23d - DMF's advantage is comparability, q24a - DMF's disadvantage is not measuring enamel lesions, q24e - DMF's disadvantage is it underestimates caries, q26f - reason for not choosing index is difficult to apply, q26n - reason for not choosing index is its complexity, q26r - reason for not choosing index is it is time consuming, q27f - prefers index due to its ease of application, q27i - prefers index due to comparability, q28 - whether would use an index other than DMF, q42c - index should be simple, q43 - whether research should be conducted to find new indices, q42m - index should be easy to apply 
because it was recommended by the WHO and MS. The younger female group who were trained at UEFS and other universities used the DMF because it was well known and easy to apply.

UFBA is the oldest university in the region, with a higher average age of the respondents, which may explain the greater concern to follow the norms of the WHO and MS, while the UEFS has a lower average age of those interviewed who were more concerned with the ease of application of the method.

Comparability was the most cited reason for choosing an index and the second most commonly reported advantage of the DMF. A concern with being able to later compare one's findings in an oral health survey is commendable because every well-trained researcher does so. However, this preference might be establishing a vicious cycle because only the DMF index is used. The only data available for comparison are those in this index; if other methods developed to detect caries in a population are never used, then other comparisons are not possible.

Difficulties in calibration and time consumption were the reasons mentioned not to use an index, suggesting that the use of a large-scale index depends on its simplicity. This finding is in accordance with the most frequently cited reason by the group interviewed for preferring an index (i.e., its ease of application), so the respondents are concerned about using a method that is quick and easy to apply.

Ease of application was cited as the main reason for preferring an index and the most frequently cited advantage of the DMF. However, if an index is used because it is the easiest but not because it is the best, then new methods that more accurately assessing this disease will never be developed [7]. A new method to assess caries might be more difficult to use; however, its results might be better as demonstrated by other studies $[4,24]$. To assess whether a change is necessary, studies that compare indices and perform cost-benefit analyses are essential.

Most respondents would use a new method to detect dental caries. It was suggested that new indices should be simple, easy to apply, and overcome the DMF's limitations. These findings show that much of this academic community was open to accepting changes in the paradigm of how to assess caries in a population, contrary to Ismail's [3] criticism of the dental community, for being extremely conservative and slow to accept changes.

Several interviewees noted the need to use indices that assess non-cavitated enamel lesions, which is in accordance with what many authors have made this argument in the literature $[3,25]$; they believe that this change is fundamental to improve the planning of health actions based on oral health surveys.
According to Pitts [26], complex and strong barriers prevent the implementation of new caries detection methods. In the present study, the potential barriers detected, in the studied group, included a lack of knowledge of new possibilities for measuring caries in a population, the prospect of being unable to compare data after using new indices, and a belief in the possibility that new indices would be more complex and difficult to apply to measure enamel lesions. It is essential to break down these barriers and use the best tools in teaching and research because it is through caries assessment methods that the presence of this disease is assessed and strategies outlined to combat it and prevent its occurrence in a population.

Using the DMF to diagnose caries lesions leads to underestimation of caries because non-cavitated enamel lesions are ignored, thereby obstructing earlier diagnoses of the disease, which might enable planning health actions more focused on dental caries prevention.

The current study revealed some of the barriers that exist regarding the implementation of new methods, indicating the necessity of a greater discussion on the subject and showing a dissatisfaction with the current methods that are often chosen for convenience because they are easy and known. Despite the local nature of this study, it can be assumed that many other regions and cities would show similar results.

Thus far, we have not found another study that has investigated the knowledge and reasons leading to the choice of caries measurement methods in the population; as such, this information is new and should stimulate reflection on this important subject. The professionals of the area should know about the advantages and disadvantages of the various methods so that they can seek better methods to measure dental caries.

According to Ismail [3], the dental community has paid little or no attention to the complex problem of caries assessment and diagnosis. However, it is necessary to change the paradigm of caries detection levels because detecting caries at an early stage, before cavitation, can have a significant effect on the population's oral health.

Conferences, panel discussions, and other activities should occur at universities and public oral health congresses to provide further discussion of the reasons for teaching and using a particular caries detection method to discuss the best way to assess caries in a population.

\section{Study limitations}

This exploratory study aimed to unveil the reasons why professionals do not use new methods to measure caries. It is a local study, and therefore, its results cannot be generalised, and inferences cannot be made because the answers might differ across other cities and countries. Studies in different places should be conducted to verify whether other reasons exist for resistance to the 
implementation of new indices and whether the level of knowledge of the indices differs from that found in the present study.

\section{Conclusions}

The DMF index was the best-known method and used by all respondents in teaching, research, and epidemiological caries surveys. The interviewed professionals had little knowledge of, and had seldomly used, other caries assessment methods.

Some professionals at major universities such as UFBA remain conservative because they knew of other indices but preferred to continue using the DMF because of its comparability and the fact that it is recommended by the WHO and MS. Another group composed of females who graduated from UEFS or other universities and who were younger used the DMF because it is well-known, simple, and easy to apply.

Many of the respondents demonstrated a desire for change and were critical of the DMF, although they neither knew nor used many of the current alternatives that seek to overcome the limitations of this index.

\section{Additional file}

Additional file 1: Questionnaire about the knowledge and use of caries indices in the context of research and teaching over the last 10 years. Questionnaire applied during the interviews. (DOCX $23 \mathrm{~kb}$ )

\section{Acknowledgements}

The authors thank the interviewed professors and researchers who generously donated their valuable time to be interviewed.

\section{Availability of data and materials}

The datasets used and/or analysed during the current study are available from the corresponding author on reasonable request.

\section{Authors' contributions}

ALSC, CMCM, and MIPV designed the study; ALSC conducted the interviews; ALSC drafted the manuscript; and ALSC and CMCM performed the statistical analyses. All authors reviewed the original draft as well as read and approved the final manuscript

\section{Ethics approval and consent to participate}

The individuals were interviewed after being properly informed about the procedures of the study and signing an informed consent document. The work was approved by the Research Ethics Committee of the Sciences Institute of the Federal University of Bahia, under CAAE number 485001152.0000 .5662

\section{Consent for publication}

Not applicable

\section{Competing interests}

The authors declare that they have no competing interests to disclose.

\section{Publisher's Note}

Springer Nature remains neutral with regard to jurisdictional claims in published maps and institutional affiliations.

\section{Author details}

'Department of Health, State University of Feira de Santana, Transnordestina, s/n, Novo Horizonte, Feira de Santana, Bahia CEP 44036-900, Brazil. ${ }^{2}$ Department of Public Oral Health, School of Dentistry, Federal University of Bahia, Araújo Pinho, 62, Canela, Salvador, Bahia CEP 40110040, Brazil.

${ }^{3}$ Postgraduate Studies in Interactive Processes of Organs and Systems, Health Science Institute, Federal University of Bahia, Avenida Reitor Miguel Calmon,

1272, Salvador, Bahia CEP 40231300, Brazil.

Received: 21 December 2017 Accepted: 13 August 2018

Published online: 29 August 2018

\section{References}

1. Leal SC, Ribeiro APD, Frencken JE. Caries assessment Spectrum and treatment (CAST): a novel epidemiological instrument. Caries Res. 2017:51:500-6.

2. Klein H, Palmer CE, Knutson JW. Studies on dental caries: I. Dental status and dental needs of elementary school children. Public Health Rep 1896-1970. 1938:751-65.

3. Baelum F, Ole V. How big is the problem? Epidemiological features of dental caries. Dent caries dis its Clin Manegement. 3rd ed. UK: Oxfort, Wiley Blackwell; 2015. p. 21-41.

4. Nyvad B, Machiulskiene V, Baelum V. Reliability of a new caries diagnostic system differentiating between active and inactive caries lesions. Caries Res. 1999;33:252-60

5. Bratthall D. Introducing the significant caries index together with a proposal for a new global oral health goal for 12-year-olds. Int Dent J. 2000;50:378-84.

6. Sheiham A, Maizels J, Maizels A. New composite indicators of dental health. Community Dent Health. 1987:4:407.

7. Castro ALS, Vianna MIP, de Reis SRA. A new index for measuring dental caries: a reversible index of dental caries-IRCD. Rev Fac Odontol Univ Fed Bahia. 1999:19:35-40.

8. Monse B, Heinrich-Weltzien R, Benzian H, Holmgren C, van Palenstein Helderman W. PUFA-an index of clinical consequences of untreated dental caries. Community Dent Oral Epidemiol. 2010;38:77-82.

9. Cruz RKS. Dental caries severity index: construction and validation [Internet]. Brasil; 2016 [cited 2017 Feb 9]. Available from: http://repositorio.ufrn.br:8080/ jspui/bitstream/123456789/21756/1/RayanneKarinaSilvaCruz_DISSERT.pdf

10. Mount GJ, Hume WR. A revised classification of carious lesions by site and size. Quintessence Int. 1997;28:301-3.

11. Ismail Al, Sohn W, Tellez M, Amaya A, Sen A, Hasson H, et al. The international caries detection and assessment system (ICDAS): an integrated system for measuring dental caries. Community Dent Oral Epidemiol. 2007;35:170-8

12. Frencken JE, de Amorim RG, Faber J, Leal SC. The caries assessment Spectrum and treatment (CAST) index: rational and development. Int Dent J. 2011:61:117-23.

13. Souza AL, Bronkhorst EM, Creugers NH, Leal SC, Frencken JE. The caries assessment Spectrum and treatment (CAST) instrument: its reproducibility in clinical studies. Int Dent J. 2014;64:187-94.

14. Braun A, Guiraud LMJC, Frankenberger R. Histological validation of ICDAS II and radiological assessment of occlusal carious lesions in permanent teeth. Odontology. 2017:105:46-53.

15. de Souza AL, Leal SC, Bronkhorst EM, Frencken JE. Assessing caries status according to the CAST instrument and WHO criterion in epidemiological studies. BMC Oral Health. 2014;14:119.

16. e-MEC - 2 v.3.262.0-2775 [Internet]. [cited 2017 Dec 14]. Available from: http://emec.mec.gov.br/

17. Arouca R, Pereira H, Alves L. Demographic Census of the Labor Force in Dental Specialties: Brazil, vol. 1; 2010. p. 2012.

18. R Core Team. R.: A language and environment for statistical computing Vienna: R Foundation for Statistical Computing; 2013. URL https://www. r-project.org/

19. Hair JF, Black WC, Babin BJ, Anderson RE, Tatham RL. Multivariate data analysis (vol 6). Porto Alegre: Brazil Bookman; 2009

20. de Melo Costa S, Prado MCM, Andrade TN, Araújo EPP, de Souza W, Junio $S$, et al. Profile of the professional of higher level in the teams of the family health strategy in Montes Claros, Minas Gerais, Brasil. Rev Bras Med Fam E Comunidade. 2013;8:90-6. 
21. Morita MC, Haddad AE, Araújo ME. Current profile and trends of the Brazilian dental surgeon. Dental Press. 2010;

22. Baldissera R dos S, Grecca FS, dos Santos RB. The woman in dentistry: from Ohio to Rio Grande do Sul. Rev Fac Odontol Porto Alegre Porto Alegre RS; 2010. p. 27-30

23. Vasconcellos E da CC, Brisolla SN, others. Female presence in the study and work of science at Unicamp. Cad Pagu. 2009;32:215-265.

24. Frencken JE, de Souza AL, van der Sanden WJ, Bronkhorst EM, Leal SC. The caries assessment and treatment (CAST) instrument. Community Dent Oral Epidemiol. 2013;41:e71-7.

25. Castro ALS, Vianna MIP, Mendes CMC. Comparison of caries lesion detection methods in epidemiological surveys: CAST, ICDAS and DMF. BMC Oral Health. 2018;18:122.

26. Pitts N. Detection, assessment, diagnosis and monitoring of caries. Karger Basel (Switzerland): 2009

Ready to submit your research? Choose BMC and benefit from:

- fast, convenient online submission

- thorough peer review by experienced researchers in your field

- rapid publication on acceptance

- support for research data, including large and complex data types

- gold Open Access which fosters wider collaboration and increased citations

- maximum visibility for your research: over $100 \mathrm{M}$ website views per year

At BMC, research is always in progress.

Learn more biomedcentral.com/submissions 